\title{
Establishment of a new relationship between posed smile width and lower facial height: A cross-sectional study
}

\author{
Aby Abraham ${ }^{1}$, Jinu George ${ }^{1}$, Elbe Peter ${ }^{1}$, Koshi Philip ${ }^{1}$, Rajesh Chankramath ${ }^{2}$, \\ Dexton Antony Johns ${ }^{3}$, Anitha Bhaskar ${ }^{4}$
}

Correspondence: Dr. Dexton Antony Johns

Email: dextonjohns@gmail.com

\begin{abstract}
'Department of Orthodontics, Government Dental College, Kottayam, Kerala, India,

2Department of Prosthodontics, Government Dental College, Kottayam, Kerala, India,

${ }^{3}$ Department of Endodontics, KMCT Dental College, Kozhikode, Kerala, India,

${ }^{4}$ Department of Community Medicine, Government

Medical College, Kottayam, Kerala, India
\end{abstract}

\section{ABSTRACT}

Objective: The present study is intended to add a new parameter that would be useful in orthodontic clinical evaluation, treatment planning, and determination of vertical dimension (at occlusion). Materials and Methods: Standardized videographic recording of 79 subjects during posed smile was captured. Each video was then cut into 30 photos using the free studio software. The widest commissure-to-commissure posed smile frame (posed smile width [SW]) was selected as one of 10 or more frames showing an identical smile. Lower third of the face is measured from subnasale to soft tissue menton using a digital vernier caliper. Two values were then compared. Ratio between lower facial height and posed SW was calculated. Results: The co-relation between smiling width and lower facial height was found to be statistically significant $(P<0.01)$. The ratio of lower facial height and smiling width was calculated as 1.0016 with a standard deviation $(\mathrm{SD})=0.04$ in males and 1.0301 with an $\mathrm{SD}=0.07$ in females. The difference between the mean lower facial height in males and females was statistically significant with a $t=10.231$ and $P=0.000$. The difference between the mean smiling width in males and females was also statistically significant with a $t=5.653$ and $P=0.000$. Conclusion: In class I subjects with pleasing appearance, normal facial proportions, normal overjet and overbite, and average Frankfort mandibular angle, the lower facial height (subnasale to soft tissue menton) is equal to posed SW.

Key words: Lower face height, posed smile width, vertical facial proportion

\section{INTRODUCTION}

Smile analysis and smile design are very important in orthodontic diagnosis and treatment planning. Recent advances in technology now permit the clinician to measure dynamic lip-tooth relationships and incorporate that information into the orthodontic problem list and treatment plan. Digital photography along with videography is useful in both smile analysis and patient communication.
Facial attractiveness is defined more by smile than by soft tissue relationship at rest. There are two types of smile: The posed or social smile, and the emotional smile ${ }^{[1]}$ The social smile is reproducible, ${ }^{[1]}$ and is the one presented to world routinely. The emotional smile varies with the emotion being displayed. The social or posed smile is the focus of orthodontic diagnosis. ${ }^{[2]}$

If the smile is typical for a particular individual, a posed smile is natural, but the smile also can be "forced" to

\footnotetext{
How to cite this article: Abraham A, George J, Peter E, Philip K, Chankramath R, Johns DA, et al. Establishment of a new relationship between posed smile width and lower facial height: A cross-sectional study. Eur J Dent 2015;9:394-9. 
mimic an unposed smile. In the latter circumstance, the smile cannot be sustained and will seem to be strained and unnatural. In the Peck classification, ${ }^{[3]}$ stage II smile is a "forced" or strained posed smile resulting in maximal upper lip elevation. Thus, two types of posed smiles are possible: Strained and unstrained. When a person is asked to pose for a photograph, the smile that is desired is a voluntary, unstrained, static, yet natural smile. Posed smiles gain importance in dentistry and orthodontics mainly because they are repeatable over time. An attractive, well-balanced smile is a paramount treatment objective of modern orthodontic therapy.

Vertical facial proportions in frontal and lateral views are best-evaluated in the context of the facial thirds, which the renaissance artists noted were equal in height in well-proportioned faces. ${ }^{[2]}$ In modern Caucasians, the lower third often is slightly longer than the central third. ${ }^{[4]}$ The lower third can further be divided into thirds: The mouth should be at one-third of the way between the base of the nose and chin.

Throughout the orthodontic literature, one can find static profile photographs and lateral cephalograms have been the key diagnostic aids in analyzing patient's profile and lip at rest. ${ }^{[3,5-8]}$ However, to best study a smile, and advance beyond static pictures, recent articles have established a new method of capturing a dynamic smile. ${ }^{[1,9-13]}$ This method uses videography and computer software to record a smile.

Method of eliciting posed smile was different in various studies. Desai et al. ${ }^{[12]}$ asked the subject to hold two rulers with cross configuration near their chin and were given instructions to say "Chester eats cheesecake by Chesapeake," relax and then smile. Walder et al. ${ }^{[1]}$ gave verbal and visual directive. The verbal directive was "give me a nice big smile, one that shows your teeth." Visual directive was a poster with color photographs of six people smiling broadly and the subject was asked to smile like the people in the photo. van der Geld et al. ${ }^{[13]}$ made the subjects to smile by showing practical jokes and spontaneous and posed smiles were obtained. The subjects wore glasses with a clipped on reference standard to enable calibration. A video camera was used and object to source distance was 4 feet, 4 feet 7 inches and $55 \mathrm{~cm}$ in studies by Desai et al., ${ }^{[12]}$ Walder et al., ${ }^{[1]}$ and van der Geld et al., ${ }^{[13]}$ respectively. The video obtained was cut into photos using video editing software.${ }^{[1,12]}$ Analysis of the photo was done in Adobe Photoshop CS2 by Desai et al. ${ }^{[12]}$ while selected video frames were measured with the help of Digora program for dental radiography by van der Geld et al. ${ }^{[13]}$
Many studies have already described the various aspects of the smile. ${ }^{[1,9-13]}$ No literature review is available about the co-relation between posed smile width (SW) and lower facial height of the patient. The null hypothesis for the study is that posed SW and lower face height (LFH) are not related. The purpose of the study was to establish a ratio between the posed SW and lower facial height in South Indian population and to add a new parameter that would be useful in orthodontic clinical evaluation and treatment planning.

\section{MATERIALS AND METHODS}

Approval wasobtained from Institutional Review Board (Dental College, Kottayam, IEC/M/06/2014/DCK). BDS students of Government Dental College, Kottayam in the age range of 18-25 years who were willing to participate in the study were screened after obtaining informed consent. The inclusion criteria were ethnic south Indian origin, class I molar relationship, class I canine relationship, normal overjet and overbite, pleasing appearance, normal face height, orthognathic profile, and an average clinical Frankfort mandibular angle (FMA). All the subjects selected were having the mesoprosopic facial form (facial index of 84.0-87.9), well-proportioned and balanced faces. Cephalometric examination of the subjects was not done because of the ethical issues. The exclusion criteria were subjects with the skeletal discrepancy, prior orthodontic treatment, history of extraction, high or low clinical FMA. 79 students (44 females and 35 males) out of the 240 screened who met the selection criteria were taken as study subjects.

A video was captured of the subject in posed smile. For posed smiles, each subject was asked to pose an enjoyment smile as realistically as possible, after being shown the proper way in a sample video. Indelible pencil markings were placed at the corner of the mouth. The video recording was done with a digital video camera (EOS 600D, CMOS sensor, DIGIC-4, Canon, Tokyo, Japan). During recording the subjects were in a standing position. The camera was tripoded $50 \mathrm{~cm}$ from the patient. A scale mounted on an adjustable stand was positioned horizontally below the mandible in the same plane of smile to avoid magnification factor in recording [Figure 1]. The video was then cut into 30 photos using a software (Free Studio). The widest commissure-to-commissure posed smile frame (posed SW) was selected as one of 10 or more frames showing an identical smile [Figure 2]. The cut photo was put into Adobe Photoshop CS6 and perpendicular was dropped to the scale and readings were obtained. 


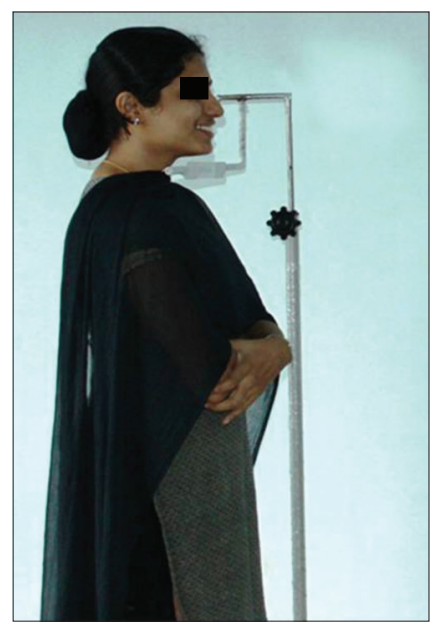

Figure 1: A scale mounted on an adjustable stand was positioned horizontally below the mandible

Sn-Me' distance was measured by hanging a vertical string with a weight (subject in natural head position), and these points were marked accordingly on the string. The marked distance is measured as the true vertical distance between Sn and Me' using digital vernier caliper. The subjects were videotaped on the same day as the measurement of LFH was taken. Both the measurements were taken by a single trained rater (principal investigator). LFH and posed SW were calculated again on $20 \%$ of the sample population and reliability of the measurements was assessed.

\section{Statistical analysis}

Using SPSS for Windows, (Version 16.0. SPSS Inc., Chicago). mean and standard deviations (SDs) were calculated, and the ratio between lower facial height and smiling width was established.

\section{RESULTS}

The results were expressed as mean and SD; the mean lower facial height of females was $62.82 \mathrm{~mm}$ with an $\mathrm{SD}=3.112$. The mean lower facial height of males was $69.23 \mathrm{~mm}$ with a SD $=2.276$. The difference between the above two means was significant with a $t=10.231$ and $P=0.000$ [Table 1]. The mean posed SW of females was $64.59 \mathrm{~mm}$ with the $\mathrm{SD}=3.706$. The mean posed SW of males was $69.34 \mathrm{~mm}$ with the $\mathrm{SD}=3.718$. There was statistically significant difference between the mean posed SW of males and females with a $t=5.653$ and $P=0.000$ [Table 2]. The co-relation between posed SW and lower facial height [Table 3] was done, and a statistically significant $(P<0.01)$ result was obtained. The scatter diagram also shows this positive co-relation [Diagram 1]. The ratio of lower facial height and posed SW was calculated

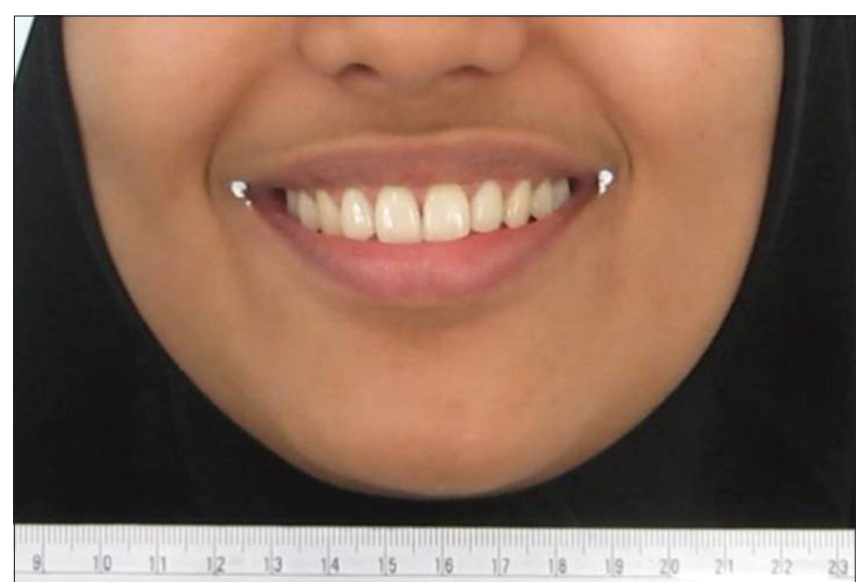

Figure 2: Posed smile photograph (obtained from video clip using free studio software)

as 1.0016 in males with an SD $=0.04$ and 1.0301 in females with an SD $=0.07$ [Table 4]. Reliability of the measurements showed a Cronbach's Alpha value (ICC) of 0.972 and 0.869 , respectively, for LFH and posed SW.

\section{DISCUSSION}

Many facial proportions have already been established to evaluate an ideal face. The artists of the Renaissance period, primarily da Vinci and Durer, established the proportion that are used in drawing anatomically correct faces. ${ }^{[2]}$ They concluded that distance from hairline to base of nose, base of nose to bottom of nose, bottom of nose to chin should be the same. ${ }^{[2]}$ Farkas' showed that in modern Caucasians of European descent, the lower third is slightly longer than the middle and upper third. ${ }^{[4]}$ The neoclassical canon of facial proportions divides the face vertically into fifths, with the width of each eye, the intercanthal distance, and the nasal width all measuring one-fifth. However, studies using direct anthropometry and photogrammetric analysis in whites and Asian subjects found variations in these proportions, with the width of the eyes and nasal widths often being either less than or greater than the inter canthal distance. ${ }^{[2,14,15]}$ Nasal tip projection can be measured using different parameters. The Baum ratio is calculated by dividing the length of a line from the nasion to the nasal tip by the length of a perpendicular line from the nasal tip to a vertical line from the subnasale. The Simons ratio also reflects nasal tip projection and is found by dividing the length from the subnasale to the nasal tip by the length from the subnasale to the superior labium. According to Powell and Humphreys, ${ }^{[16]}$ the ideal Baum and Simons ratios for whites are 2.8:1 and 1, respectively. The posed SW and lower facial 


\begin{tabular}{|c|c|c|c|c|c|c|}
\hline & Sex & $n$ & Mean & SD & $t$ & $P$ \\
\hline \multirow[t]{2}{*}{$\overline{\mathrm{LFH}}$} & Females & 44 & 62.82 & 3.112 & 10.231 & 0.000 \\
\hline & Males & 35 & 69.23 & 2.276 & & \\
\hline \multicolumn{7}{|c|}{ SD: Standard deviation, LFH: Lower facial height } \\
\hline \multicolumn{7}{|c|}{ Table 2: Mean and SD of smiling width } \\
\hline & Sex & $n$ & Mean & SD & $t$ & $P$ \\
\hline \multirow[t]{2}{*}{ SW } & Females & 44 & 64.59 & 3.706 & 5.653 & 0.000 \\
\hline & Males & 35 & 69.34 & 3.718 & & \\
\hline \multicolumn{7}{|c|}{ SD: Standard deviation, SW: Smile width } \\
\hline \multicolumn{7}{|c|}{$\begin{array}{l}\text { Table 3: Co-relation between LFH and smiling width } \\
\text { shows a statistically significant }(P<0.01) \text { relation }\end{array}$} \\
\hline & & & & Sex & & LFH \\
\hline \multicolumn{7}{|l|}{ Sex } \\
\hline \multicolumn{3}{|c|}{ Pearson correlation } & & 1 & & $0.758^{* *}$ \\
\hline \multicolumn{3}{|c|}{ Significant (2-tailed) } & & & & 0.000 \\
\hline \multicolumn{3}{|l|}{$n$} & & 79 & & 79 \\
\hline \multicolumn{7}{|l|}{ LFH } \\
\hline \multicolumn{3}{|c|}{ Pearson correlation } & \multicolumn{2}{|c|}{$0.758^{* *}$} & & 1 \\
\hline \multicolumn{3}{|c|}{ Significant (2-tailed) } & \multicolumn{2}{|c|}{0.000} & & \\
\hline \multicolumn{2}{|l|}{$n$} & & \multicolumn{2}{|r|}{79} & & 79 \\
\hline
\end{tabular}

\begin{tabular}{|c|c|c|c|c|}
\hline & Sex & $n$ & Mean & SD \\
\hline \multirow[t]{2}{*}{ SW/LFH } & Females & 44 & 1.0301 & 0.07003 \\
\hline & Males & 35 & 1.0016 & 0.04032 \\
\hline
\end{tabular}

height would be yet another ratio to this list of normal proportions for artistic facial evaluation.

The videographic method of facial smile evaluation used in this study showed to be a reliable method of smile quantification because a more standardized smile could be obtained minimizing the inherent error of a single snapshot. ${ }^{[1,9-11]}$

van der Geld et al. ${ }^{[13]}$ made the subjects to wear glasses with a clipped on reference standard to enable calibration. In a study by Desai et al., ${ }^{[12]}$ subjects were asked to smile while holding rulers with cross configuration near their chin. Once the video was cut and photo selected, the analysis was done by Adobe Photoshop CS2 and measurement was done by an indirect method by converting pixels into millimeter. In the above methods, the ruler and smile are in two different planes. The measurements obtained will differ from actual values. In order to eliminate this error, an adjustable stand was specifically made for the study, which could place the scale in the same

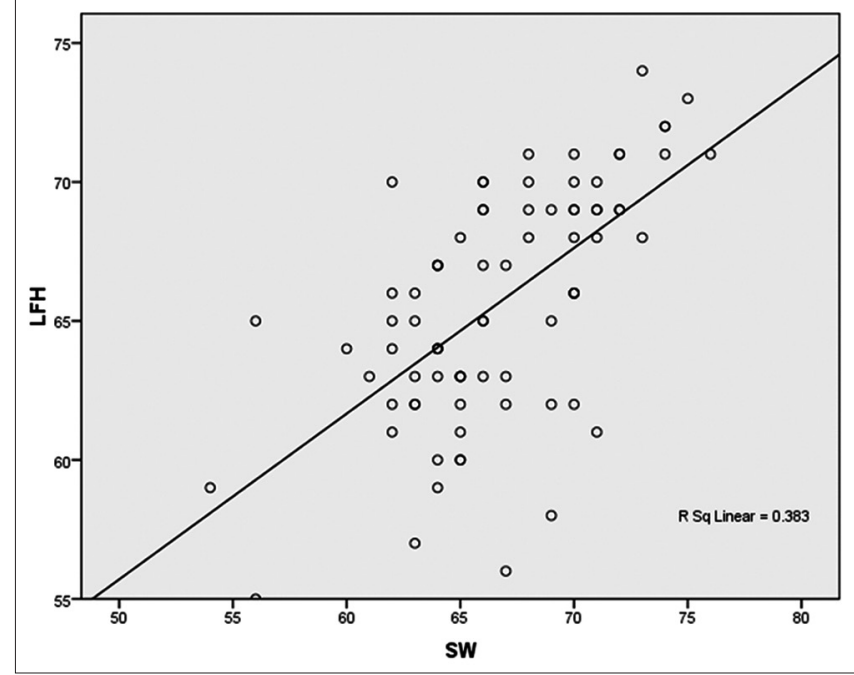

Diagram 1: The scatter diagram also shows a positive co-relation (LFH: Lower facial height; SW: Smile width)

vertical plane of smile. A direct method was followed while analyzing smile, that is, the cut photo was put into Adobe Photoshop CS6, and perpendicular was dropped to the scale and reading was obtained.

The mean of the ratio between posed SW and lower facial height for South Indian population was calculated as 1.00 in males and 1.03 in females. From this study, one can conclude that class I subjects with pleasing appearance, normal overjet and overbite should depict a 1:1 ratio between LFH (measured from subnasale to soft tissue menton) and posed SW (measured from outer commissure to outer commissure). SW from outer commissure to outer commissure was found to be 69.34 for males (SD - 3.718) and 64.59 (SD - 3.706) for females in the present study.

The LFH measured from subnasale to soft tissue menton in this study showed a value of 69.23 (SD - 2.276) for males and 62.82 (SD - 3.112) for females. LFH of the various population is summarized in Table 5 . According to Arnett et al., ${ }^{[17]}$ mean value for lower one-third facial height was $71 \pm 3.5 \mathrm{~mm}$ for females and $81.1 \pm 4.7 \mathrm{~mm}$ for males. The mean value of lower $1 / 3^{\text {rd }}$ of the face (Iraq population) ${ }^{[18]}$ for males was found to be $68.63 \pm 4.21 \mathrm{~mm}$ and for females was found to be $63.03 \pm 3.72 \mathrm{~mm}$. A Turkish sample ${ }^{[19]}$ showed a mean lower facial height $76.5 \pm 5.5 \mathrm{~mm}$ for males and $68.7 \pm 4.5 \mathrm{~mm}$ for females. Chhajed et al. ${ }^{[20]}$ study in Central Indian population (Madhya Pradesh) found out that lower facial height for males was $61.08 \pm 0.5423 \mathrm{~mm}$ and for females was $55.40 \pm 3.92 \mathrm{~mm}$. A study on Andhra Pradesh population by Sinojiya et al. ${ }^{[21]}$ found that lower $1 / 3^{\text {rd }}$ of the face for females was $55.13 \pm 3.40 \mathrm{~mm}$ and for males was $58.88 \pm 2.20 \mathrm{~mm}$. 


\begin{tabular}{|c|c|c|}
\hline Population & Males & Females \\
\hline Whites $^{[17]}$ & $81.1 \pm 4.7$ & $71 \pm 3.5$ \\
\hline Turkish sample ${ }^{[19]}$ & $76.5 \pm 5.5$ & $68.7 \pm 4.5$ \\
\hline Iraq population ${ }^{[18]}$ & $68.63 \pm 4.21$ & $63.03 \pm 3.72$ \\
\hline Central Indian population ${ }^{[20]}$ & $61.08 \pm 0.54$ & $55.40 \pm 3.92$ \\
\hline Andhra Pradesh population ${ }^{[21]}$ & $58.88 \pm 2.20$ & $55.13 \pm 3.40$ \\
\hline North Indian population ${ }^{[22]}$ & $73.31 \pm 2.80$ & $66.50 \pm 4.72$ \\
\hline South Indian population ${ }^{[23]}$ & $72.40 \pm 7.41$ & $63.13 \pm 9.07$ \\
\hline
\end{tabular}

Upadhyay et al. ${ }^{[22]}$ conducted a study to compare the standard soft tissue cephalometric analysis norms with norms derived for population of Western Uttar Pradesh region of India. Lower $1 / 3^{\text {rd }}$ of the face for females was found to be $66.500 \pm 4.7269 \mathrm{~mm}$ and for males was found to be $73.313 \pm 2.8040 \mathrm{~mm}$. A study on South Indian population by Kalha et al..$^{[23]}$ had results of lower facial height similar to the one obtained in the present study. Lower $1 / 3^{\text {rd }}$ of the face for females was found to be $63.13 \pm 9.07 \mathrm{~mm}$ and for males was found to be $72.40 \pm 7.41 \mathrm{~mm}$.

The esthetic ratio between LFH and posed SW would be a new tool in the artistic facial evaluation. Loss of vertical dimension in patients with chronic attrition as in Bruxism or other parafunctional habit may benefit from this finding as the posed SW in such patients may be used as a guide in restoring their lost vertical dimension. In orthodontics, this parameter could be used in deciding the amount of bite opening in deep bite cases. From an orthognathic surgery perspective, the ratio might aid in determining LFH in vertical maxillary deficiency and the extent of maxillary inferior positioning, but further studies are required to validate this. In addition, this ratio can be added as a new factor in the evaluation of smile aesthetics. From this study, it is concluded that in class I subjects with normal overjet, overbite and FMA, posed SW is equal to LFH. However, if LFH is intentionally increased or decreased by orthodontic therapy (molar extrusion/intrusion), how the smiling width change remains unclear and needs further study. Chou et al. [24] reported that with an increase in vertical dimension, there would not be any change in posed SW. In clinical practice, we commonly encounter patients with loss of vertical dimension. Further studies about posed SW are required in cases with loss of vertical dimension for evaluating whether it can be used in complete denture rehabilitations.

A smaller sample size is one the primary limitation of the study. The ratio was obtained in a particular population, and this is yet another limitation. LFH and posed SW relationships in class II and class III subjects with different growth patterns need to be assessed further. A study about the relationship of LFH and posed SW should be done a larger sample and on different population groups to finally use this ratio in clinical evaluation and treatment planning.

\section{SUMMARY AND CONCLUSIONS}

- This study focused on deriving a ratio between the posed SW and lower facial height in normal subjects

- A 1:1 ratio could be established in normal individuals with a pleasing appearance and normal overjet and overbite. This parameter can be a new tool in the armamentarium of an orthodontist or a cosmetic dental surgeon in evaluating the dynamic facial esthetics for smile designing

- In full mouth rehabilitation cases due to bruxism, currently the vertical dimension measurement is done arbitrarily. The present result can be used as an additional parameter in determining the vertical dimension in such cases

- Further studies in this area and to other age groups can confirm whether posed SW could be used as a parameter in determining vertical dimension at occlusion for edentulous patients

- Studies with larger sample are warranted to determine the changes in smiling width in deep bite and open bite cases.

\section{REFERENCES}

1. Walder JF, Freeman K, Lipp MJ, Nicolay OF, Cisneros GJ. Photographic and videographic assessment of the smile: Objective and subjective evaluations of posed and spontaneous smiles. Am J Orthod Dentofacial Orthop 2013;144:793-801.

2. Profitt W. Contemporary Orthodontics. $2^{\text {nd }}$ ed. Mosby, St Louis 1997; p. 110.

3. Peck S, Peck L, Kataja M. The gingival smile line. Angle Orthod 1992;62:91-100

4. Farkas LG, Hreczko TA, Kolar JC, Munro IR. Vertical and horizontal proportions of the face in young adult North American Caucasians: Revision of neoclassical canons. Plast Reconstr Surg 1985;75:328-38.

5. Rigsbee $\mathrm{OH} 3^{\text {rd }}$, Sperry TP, BeGole EA. The influence of facial animation on smile characteristics. Int J Adult Orthodon Orthognath Surg 1988;3:233-9.

6. Mackley RJ. An evaluation of smiles before and after orthodontic treatment. Angle Orthod 1993;63:183-9.

7. Formby WA, Nanda RS, Currier GF. Longitudinal changes in the adult facial profile. Am J Orthod Dentofacial Orthop 1994;105:464-76.

8. Tjan AH, Miller GD, The JG. Some esthetic factors in a smile. J Prosthet Dent 1984;51:24-8.

9. Ackerman MB, Ackerman JL. Smile analysis and design in the digital era. J Clin Orthod 2002;36:221-36.

10. Sarver DM, Ackerman MB. Dynamic smile visualization and quantification: Part 1. Evolution of the concept and dynamic records for smile capture. Am J Orthod Dentofacial Orthop 2003;124:4-12.

11. Sarver DM, Ackerman MB. Dynamic smile visualization and quantification: Part 2. Smile analysis and treatment strategies. Am J 
Orthod Dentofacial Orthop 2003;124:116-27.

12. Desai S, Upadhyay M, Nanda R. Dynamic smile analysis: Changes with age. Am J Orthod Dentofacial Orthop 2009;136:310.e1-10.

13. van der Geld PA, Oosterveld P, van Waas MA, Kuijpers-Jagtman AM. Digital videographic measurement of tooth display and lip position in smiling and speech: Reliability and clinical application. Am J Orthod Dentofacial Orthop 2007;131:301.e1-8.

14. Sim RS, Smith JD, Chan AS. Comparison of the aesthetic facial proportions of southern Chinese and white women. Arch Facial Plast Surg 2000;2:113-20.

15. Wang D, Qian G, Zhang M, Farkas LG. Differences in horizontal, neoclassical facial canons in Chinese (Han) and North American Caucasian populations. Aesthetic Plast Surg 1997;21:265-9.

16. Powell N, Humphreys B. Proportions of the Aesthetic Face. New York: Thieme-Stratton; 1984.

17. Arnett GW, Jelic JS, Kim J, Cummings DR, Beress A, Worley CM Jr, et al. Soft tissue cephalometric analysis: Diagnosis and treatment planning of dentofacial deformity. Am J Orthod Dentofacial Orthop 1999;116:239-53.

18. Kadhom ZM, Al-Janabi MF. Soft-tissue cephalometric norms for a sample of Iraqi adults with class I normal occlusion in natural head position. J Bagh Coll Dent 2011;23:160-6.

19. Uysal T, Yagci A, Basciftci FA, Sisman Y. Standards of soft tissue Arnett analysis for surgical planning in Turkish adults. Eur J Orthod 2009;31:449-56.

20. Chhajed S, Kodumuru S, Singh G, Arun AV, Cholleti SK, Kothari S.
Facial Soft Tissue Cephalometric Norms in a Central Indian Ethnic Population (Madhya Pradesh). J Indian Ortod Soc 2014;48:7-13.

21. Sinojiya J, Aileni KR, Rachala MR, Pyata JR, Mallikarjun V, Reddy CM Soft tissue esthetic norms for mahabubnagar population of southern India. J Clin Diagn Res 2014;8:255-9.

22. Upadhyay JS, Maheshwari S, Verma SK, Zahid SN. Soft tissue cephalometric analysis applied to regional Indian population. Natl J Maxillofac Surg 2013;4:159-66.

23. Kalha AS, Latif A, Govardhan SN. Soft-tissue cephalometric norms in a South Indian ethnic population. Am J Orthod Dentofacial Orthop 2008;133:876-81.

24. Chou JC, Thompson GA, Aggarval HA, Bosio JA, Irelan JP. Effect of occlusal vertical dimension on lip position at smile. J Prosthet Dent 2014;112:533-9.

\begin{tabular}{|l|l|}
\hline \multicolumn{2}{|c|}{ Access this article online } \\
\hline Quick Response Code: & Website: \\
\hline & www.eurjent.com \\
\cline { 2 - 2 } & \\
\hline
\end{tabular}

